\title{
New compact open-field double-pass system with asymmetric focus
}

\section{Nuevo sistema de doble-paso compacto con enfoque asimétrico}

\author{
A. Giner ${ }^{1, S}$, M. Arjona ${ }^{1, S}$, F. Díaz-Doutón ${ }^{1}$, M. Aldaba ${ }^{1}$, C.E. García- Guerra ${ }^{1}$, F. Sanabria1 ${ }^{1}$ J. \\ Pujol ${ }^{1, S}$ \\ 1. Centre for Sensors, Instruments and Systems Development (CD6), \\ Universitat Politècnica de Catalunya (UPC), Terrassa, Barcelona, Spain \\ ${ }^{(*)}$ E-mail:anna.giner-tort@upc.edu $\quad$ S: SEDOPTICA member
}

Received: 02/12/2016 Accepted: 08/01/2018

DOI: $10.7149 /$ OPA.51.1.49057

\begin{abstract}
:
Every day more people are using multifocal systems to correct presbyopia, as for example contact lenses or intraocular lenses. As a consequence, the necessity to do an appropriate characterization of their optical quality has increased. Due to this situation, the main purpose of this project has been to develop a new compact open-field double-pass system with asymmetric focus that characterizes objectively in vivo the optical quality of multifocal systems that are adapted or implanted in the eye. As a preliminary study, one diffractive and one refractive multifocal lens were implanted in a wet customized model-eye and characterized by this new set-up. Regarding the asymmetric focus of the set-up, a through-focus from +0.75 to $-4.00 \mathrm{D}$ in steps of $0.25 \mathrm{D}$ was performed in the second pass for each tested lens,while the optical power of the first pass remained fixed. Results show that it is possible to distinguish, characterize the different foci of the measured multifocal intraocular lenses implanted in the model eye, and evaluate the optical quality of the system composed by the eye + the multifocal element. Therefore, it has been concluded that this new compact open-field double-pass system with asymmetric focus is suitable to evaluate the optical quality of multifocal systems adapted or implanted in the eye.
\end{abstract}

Key words: Presbyopia; Multifocal intraocular lenses; Double-pass; Through-focus

\section{RESUMEN:}

Cada día más personas usan elementos ópticos multifocales para corregir la presbicia, por ejemplo una lente de contacto o una lente intraocular. En consecuencia, la necesidad de evaluar la calidad óptica del ojo con un elemento corrector multifocal ha adquirido una gran importancia. Dada esta situación, el principal objetivo de este proyecto ha sido desarrollar un nuevo sistema compacto basado en la técnica de doble-paso con enfoque asimétrico capaz de realizar una caracterización objetiva e "in vivo" de la calidad óptica del conjunto ojo-elemento óptico multifocal. En este estudio preliminar se han empleado dos lentes intraoculares multifocales, una difractiva y otra refractiva, implantadas en un ojo artificial. Al ser un sistema con enfoque asimétrico, se utilizó el segundo paso para realizar un barrido desde +0.75 a $-4.00 \mathrm{D}$ en pasos de $0.25 \mathrm{D}$ manteniendo el primer paso fijo. Los resultados han mostrado que es posible hallar y diferenciar los dos planos de enfoque, lejano y cercano, de las lentes intraoculares multifocales implantadas en el ojo artificial y evaluar la calidad óptica del conjunto ojoelemento multifocal. Por tanto, se ha demostrado la viabilidad de este nuevo sistema compacto de doble-paso con enfoque asimétrico para caracterizar la calidad óptica de un ojo con un elemento óptico multifocal.

Palabras clave: Presbicia; Lentes intraoculares multifocales; Doble-paso. 


\section{REFERENCES AND LINKS / REFERENCIAS Y ENLACES}

[1] A. Glasser, M.C.W. Campbell, "Presbyopia and the optical changes in the human crystalline lens with age”, Vis Res 38(2), 209-229 (1998).

[2] J.E. Sheedy, "Optics of progressive addition lenses", Am J of Optom \& Phys Opt 64(2), 90-99 (1987).

[3] T. Ferrer-Blasco, D. Madrid-Costa, "Stereoacuity with simultaneous vision multifocal contact lenses", Optom and Vis Sci 87(9), 663-668 (2010).

[4] E.S, Bennet, "Contac lens correction of presbyopia”, Clin and Exp Optom 91(3), 265-278 (2008).

[5] R. Gil-Cazorla, S. Shah, S.A. Naroo, "A review of the surgical options for the correction of presbyopia", Brit J of Opthalm 100, 62-70 (2016).

[6] C. Fedtke, R.C. Bacaraju, K. Ehrmann, J. Chung, V. Thomas, B.A. Holden, "Visual performance of single vision and multifocal contact lenses in non-presbyopic myopic eyes", Cont Lens and Ant Eye 39, 38-46 (2016).

[7] H.S.Hwang, H.Y. Shin, C.K. Joo, "Double-pass system (optical quality analysis system) for analysis of the multifocal function of a diffractive multifocal intraocular lens (Acrysof ReSTOR®) compared to a monofocal intraocular lens (Acrysof IQ®)", J Opt Soc of Korea 18(2), 110-117 (2014).

[8] W.N. Charman, R. Montes-Mico, H. Radhakrishnan, "Problems in the measurement of wavefront aberration for eyes implanted with diffractive bifocal and multifocal intraocular lenses", J Refrac Surg 24, 280-286 (2008).

[9] D. Gatinel, "Double pass-technique limitations for evaluation of optical performance after diffractive IOL implantation", Cat and Refrac Surg 37, 621-622 (2011).

[10] F. Diaz-Douton, A. Benito, J. Pujol, J.L. Guell, P. Artal, "Comparison of the retinal image quality with a Hartmann-Shack wavefront sensor and a double-pass instrument", Invest Opthal and Vis Sci 47, 17101716 (2006).

[11] F. Sanabria, F. Díaz-Doutón, M. Aldaba, J. Pujol, "Spherical refractive correction with an electro-optical liquid lens in a double-pass system" J. Europ. Opt. Soc. Rap. Public. 8, 13062 (2013).

[12] H. Hofer, P. Artal, B. Singer, J. L. Aragón, D. R. Williams, "Dynamics of the eye's wave aberration", J. Opt. Soc. Am. A, 18 (3), 497- 506 (2001).

[13] UNE-EN 60825-1, "Seguridad de los productos laser. Parte 1: Clasificación de los equipos y requisitos", (2008).

[14] International Organization for Standardization 11979-2, “Ophthalmic implants - Intraocular lenses Part 2: Optical properties and test methods", (1999).

[15] M.B. Baamonde, "Lentes intraoculares bifocales, multifocales y acomodativas en cirugía del cristalino", $1^{\text {st }}$ Edition, SECOIR Editorial, MAC LINE S.L. (2007).

[16] T. Terwee, H. Weeber, M. van der Mooren, P. Piers, "Visualization of the retinal image in an eye model with spherical and aspheric, diffractive and refractive multifocal intraocular lenses", J Refrac Surg 24, 223-232 (2008).

[17] M. Vilaseca, A. Padilla, J.C. Ondategui, M. Arjona, J.L.Güell, J. Pujol, “Effect of laser in situ keratomileusis on vision analysed using preoperative optical quality”, J Cat Refrac Surg 36, 1945-1954 (2010).

[18] L.N. Thibos, A. Bradley, R.A. Applegate, "Accuracy and precision of objective refraction from wavefront aberrations" J Vision 4, 329-351 (2004).

[19] C. García-Guerra, M. Aldaba, M. Arjona, J. Pujol, "Binocular open-view system to perform estimations of aberrations and scattering in the human eye" A Optics 54 (32), 9504-9508 (2016).

[20] E. Fernández, I. Iglesias, P. Artal, “Closed-loop adaptive optics in the human eye” O Letters 26(10), 746748 (2001).

[21] P. Prieto, E. Fernández, S. Manzanera, P. Artal, "Adaptive optics with a programable phase modulator: Applications in the human eye" O Express 12 (17), 4059-4071 (2004).

[22] A. Barisic, I. Dekaris, N. Gabrie, M. Bohae, I. Romae, I. Mravieie, R. Lazie, "Comparison of diffractive and refractive multifocal intraocular lenses in presbyopia treatment", Coll Antropol 32(2), 27-31 (2008).

[23] B. Zelichowska, M. Rekas, A. Stankiewicz, A. Cervino, R. Montes-Mico, "Apodized diffractive versus refractive multifocal intraocular lenses: optical and visual evaluation”, J Cat Refrac Surg 34, 2036-2042 (2008). 


\section{Introduction}

Presbyopia is an age-related visual dysfunction [1] undergone by all the whole population since their midlate-40s. One of the most popular solutions to correct presbyopia are multifocal systems. They can be classified between alternating vision multifocal systems, as multifocal spectacle lenses [2], or simultaneous vision [3] multifocal systems, as multifocal contact lenses (MCLs) [4] or multifocal intraocular lenses (MIOLs) [5].

Simultaneous vision systems provide concurrent clear vision at two or more distances by the different optical designs that multifocal contact or intraocular lenses have. This means that the images corresponding to the different focal distance of the multifocal system overlap on the retina, being one a focused image and unfocused the others. These systems have very complex designs that makes difficult to characterize their optical quality in an objective way, especially in "in vivo" conditions.

Different studies using commercial double-pass systems or aberrometers to characterize MCLs or MIOLs "in-vivo" can be found in the literature [6; 7]. However, Charman et al. have reported problems for MIOLs' evaluation with aberrometers [8] and Gatinel et al. have issued possible limitations that instruments based on double-pass technique can present with different designs of MIOLs [9]. The most important limitation of the commercial instruments based on the double-pass technique, is the fact that they have a symmetric focus. This means that if the first pass is focused for the far vision the second is also focused only for the far vision. Taking into account that the double-pass systems usually work with an entrance pupil (EP) of $2 \mathrm{~mm}$ and that $2 \mathrm{~mm}$ normally corresponds to only the central vision zone in MCLs and MIOLs, a double-pass system with a symmetric focus could only evaluate properly the optical quality of the specific vision that the lenses have in their centre. Consequently, in order to evaluate the optical quality of the different visions that MCLs and MIOLs provide to their users, an asymmetric focus is needed to keep focused the retinal image created in the first pass while changing the focus of the second. Due to the current situation, the purpose of this project was to develop a new compact open-field double-pass system with asymmetric focus to characterize objectively "in-vivo" the optical quality of multifocal systems adapted or implanted in the eye.

\section{Methods}

\section{2.a. Experimental Set-up}

The customized experimental set-up is based on double-pass technique [10]. As its name indicates, the double-pass technique consists in a first pass where the image of a point source is created on the retina, and in a second pass which images the retinal reflection in an imaging device after the second pass of the light through the optics of the eye. This new experimental set-up differs mainly from the conventional doublepass designs by the fact that the control of the focal position of the first pass and the second are independent from each other. This means that the focus of the first pass and the second can be symmetric or asymmetric. The advantage of the asymmetric focus is that the system can perform a complete through-focus remaining the image of the first pass always focused on the retina. This fact is totally essential to perform a correct optical characterisation of any multifocal system.

Other improvements added in this system are the use of Electro-Optical Lenses (EOLs) instead of Badal's system to compensate the spherical refraction of the measured eye [11] and its open field configuration. Both improvements contribute to downsize the set-up (Fig. 1 and 2).

Fig. 1 shows the optical design which consists of a diode LASER of 780nm that will be focused in the retina of the measured eye passing through the first pass of the system. This first pass is composed by a $2 \mathrm{~mm}$ entrance pupil (EP), EOL 1 (EL-10-30-NIR-LD, Optotune), plate beam splitter 1 (BS1), achromatic doublet of $60 \mathrm{~mm}$ focal length (L1), a $50 \mathrm{~mm}$ diameter hot mirror (HM) and a dichroic filter (DC). The retinal reflection of the laser is then focused in the DP Camera (ORCA-Flash4.0 V2, Hamamatsu Photonics) passing through the second pass. In the second pass the light comes out to the eye and passes again through the DC, HM and L1. After that, the light is reflected by BS1 to pass through EOL 2 (EL-10-30-NIR-LD, Optotune), mirror 1(M1), afocal system (m = 1), mirror 2(M2) and a 4mm exit pupil (ExP). At the end of the system the double-pass image is focused in the DP Camera by the camera lens of $45 \mathrm{~mm}$ focal length (Camera Lens). The pupil of the measured eye is monitored by the Pupil's Camera (CLLCHATCAM C08-209, Conceptronic). 
In order to avoid speckle problems, the hot mirror was mounted on a vibrating motor to act as a scanning mirror [12], since it is a common reflective element for the first and the second pass. In addition, the laser power in the cornea was below the safety limits established by UNE-EN 60825-1 [13].

Customized software was developed to control the vibration motor, the laser, both cameras and both EOLs of this system using Matlab (Mathworks, 2010).

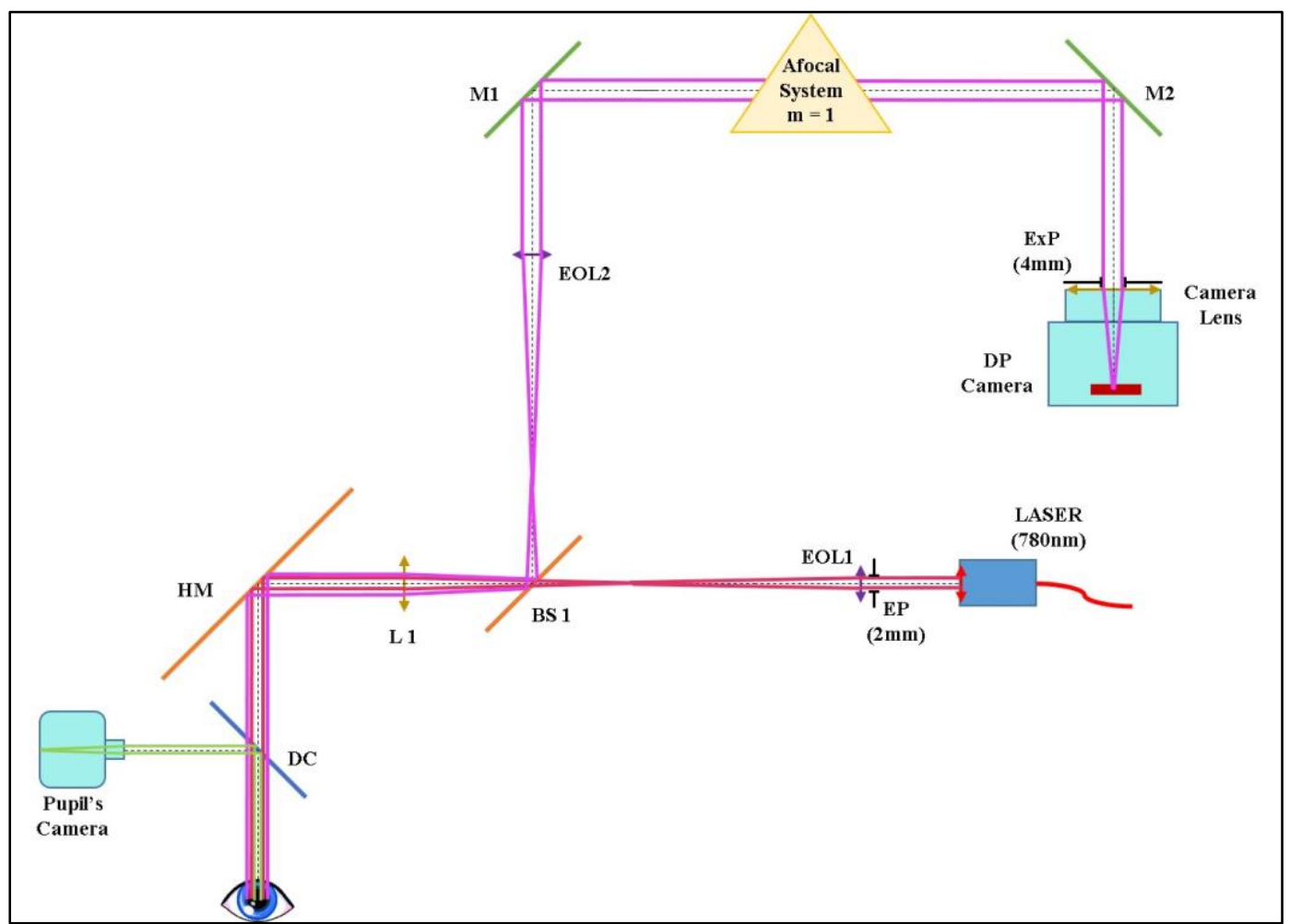

Fig.1: Optical System Design composed by LASER, EP (entrance pupil), EOL1, BS1 (beam splitter 1), L1 (lens 1), HM (hot mirror), DC (dichroic filter), Pupil`s Camera, EOL2, M1 (mirror 1), Afocal System, M2, ExP (exit pupil), Camera Lens and DP Camera (double-pass camera).

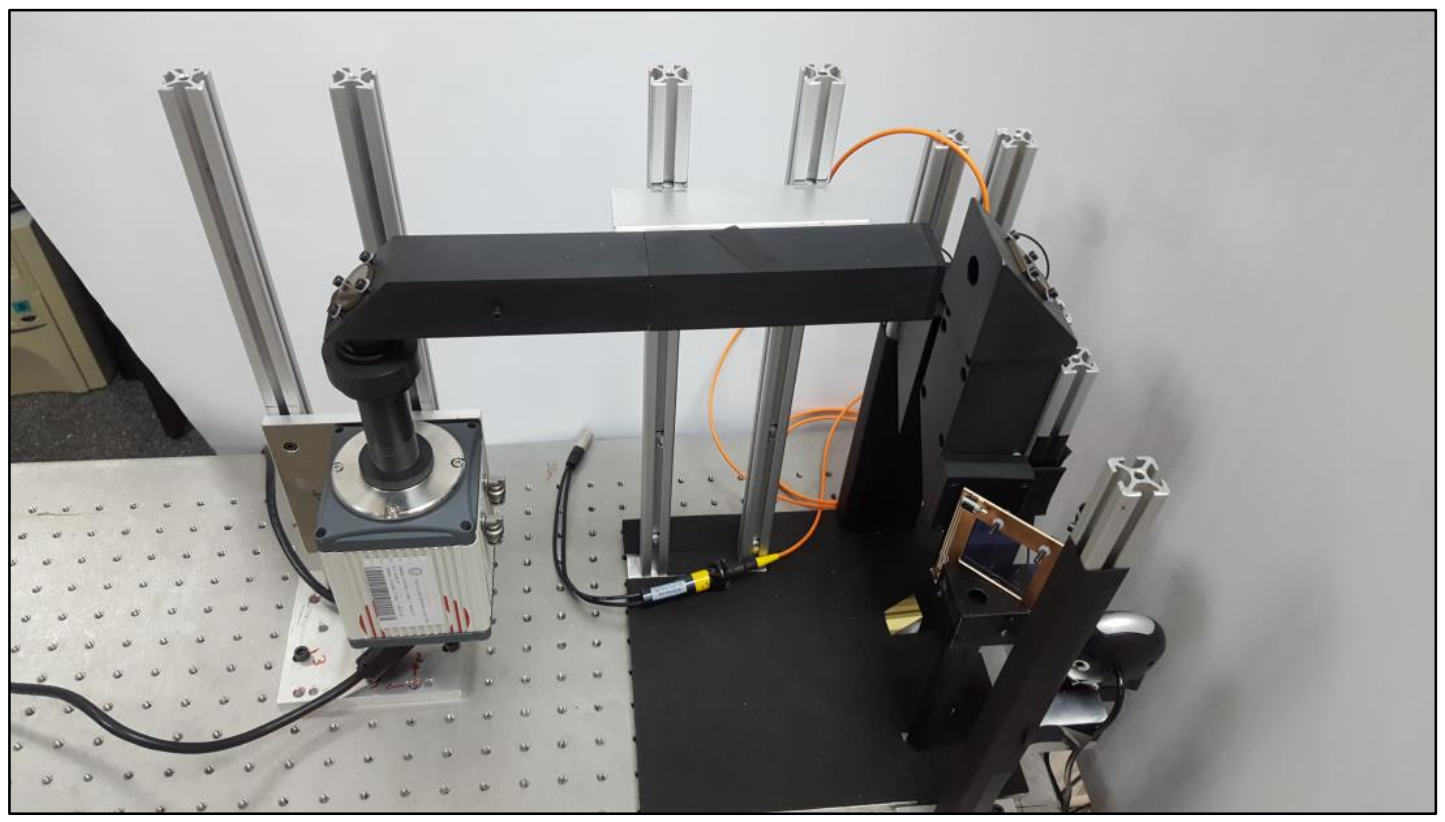

Fig. 2: Picture of the experimental set-up. 


\section{2.b. Model eye and Multifocal Intraocular Lenses}

A customized wet model eye based on 11979 ISO's regulation [14] has been used to test the functionality of the set-up (Fig. 3). It consists of an achromatic doublet acting as a cornea and the measured MIOL immersed in saline solution. Hence, the model eye has a dry zone, where the achromatic doublet is placed, and a wet zone, where the MIOL is placed. Two plane N-BK7 precision windows separate the wet zone from the dry zone. A specific holder was designed to place any existing MIOL.

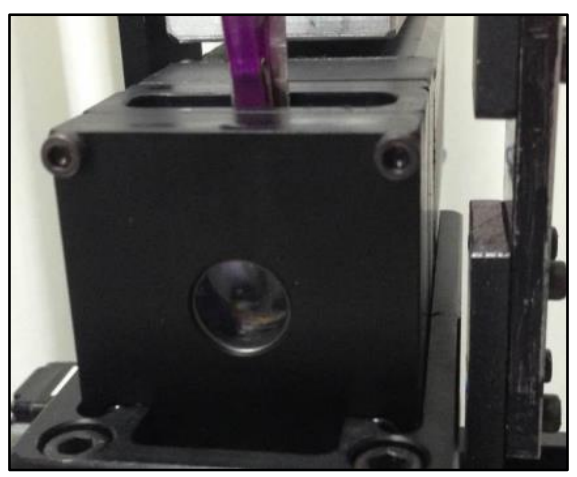

Fig. 3: Customized model eye.

In this first study two MIOLs were included: One concentric diffractive MIOL (AcrySof® IQ ReSTOR® SN6AD1, Alcon Novartis Company) (Fig. 4 (a)) and one non-concentric refractive MIOL (Precizon Presbyopic, OPHTEC B.V.) (Fig. 4 (b)). The diffractive MIOL has a large number of concentric rings with little sharp edges that create different and independent focal points thanks to constructive interferences [15]. The diffractive lens used in this study has a dioptric power of +21.0D with an addition of +3.00D. In contrast, the non-concentric refractive MIOL has an asymmetric distribution of different refractive zones that correspond to different distance visions. The refractive MIOL has a power of +20.0D with an addition of $+2.75 \mathrm{D}$. In contrast with the diffractive MIOLs that the whole optical zone contributes to all focal points, in the refractive MIOLs each refractive zone refracts the light to the associated focal point [16].

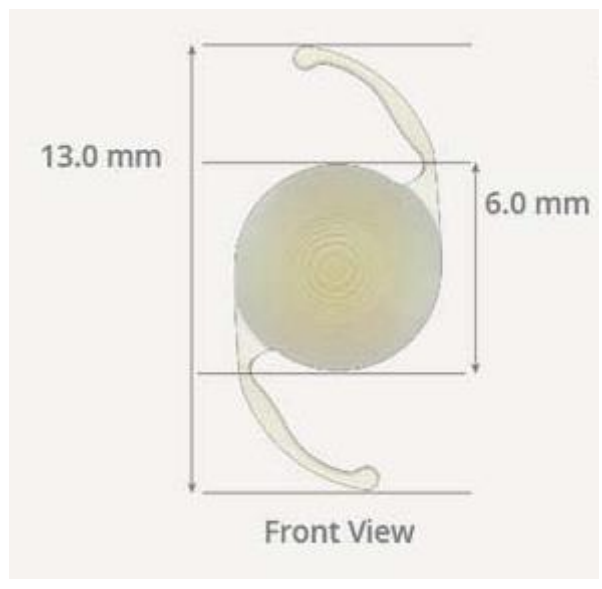

(a)

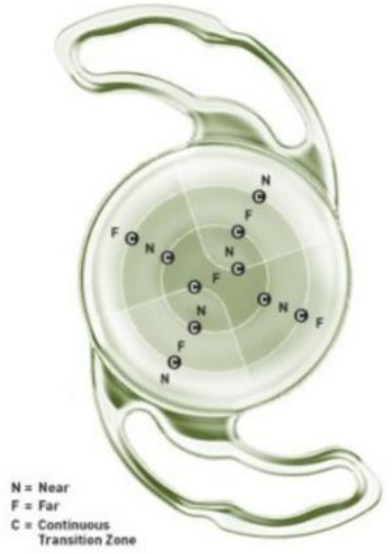

(b)

Fig. 4: (a) Scheme of the design of the MIOL AcrySof $®$ IQ ReSTOR® SN6AD1, Alcon Novartis Company. (b) Scheme of the design of the MIOL Precizon Presbyopic, OPHTEC B.V.

\section{2.c. Measurement Protocol}

Once the MIOL was well-centered, a conventional double-pass analysis was performed to be able to find the best far focus position. A conventional double-pass analysis means where the first and the second pass are symmetric. So, both EOLs change their dioptric power in the same way and time. Then, keeping the first pass at the far focus position and considering it as 0.00D, the second pass performed the through-focus changing the dioptric power of EOL 2 from $+0.75 \mathrm{D}$ to $-4.00 \mathrm{D}$ in steps of $0.25 \mathrm{D}$. This way, the system is evaluating near viewing condition from -0.75 to $+4.00 \mathrm{D}$ in steps of $0.25 \mathrm{D}$. Six images per each step were gotten. This procedure was repeated three times per each lens. 
The intensity of the laser was adjusted for far focus results and remained constant along the whole throughfocus.

\section{2.d. Data analysis}

The double-pass images captured per each step of the through-focus were averaged and from these images the double-pass image profile and the modulation transfer function (MTF) of each step were obtained. Different parameters to evaluate the optical quality of the measured eye can be calculated from them. On the first hand, the full width at half maximum (FWHM) is obtained from the double-pass image profile. It indicates the width of the double-pass image profile at the half maximum. The narrower the profile at the half maximum, the better the optical quality. On the other hand, the MTF cut-off and the Strehl ratio (SR) can be computed from the MTF. The MTF cut-off is the maximum spatial frequency that the eye is able to differentiate. The higher the cut-off, the better the optical quality. Finally, the SR can be calculated in the frequency domain $[17,18]$ as the ratio between the volumes under the MTF of the measured optical system and that of the aberration-free system. The closer to 1 the SR, the better the optical quality. The FWHM MTF cut-off and the Strehl ratio values of each double-pass image were calculated by using a customized software developed also in Matlab (Mathworks 2010).

Non-statistical analysis was performed in this study. Only a comparative analysis was performed, since the number of measurements was limited $[19,20,21]$.

\section{Results}

Four of the most representative double-pass images of the through-focus of each lens are shown in Fig. 5 and Fig. 6. The differences between the images that correspond to one of the focus and the out of focus images are very noticeable. It is also possible to distinguish differences between the refractive and the diffractive MIOL.

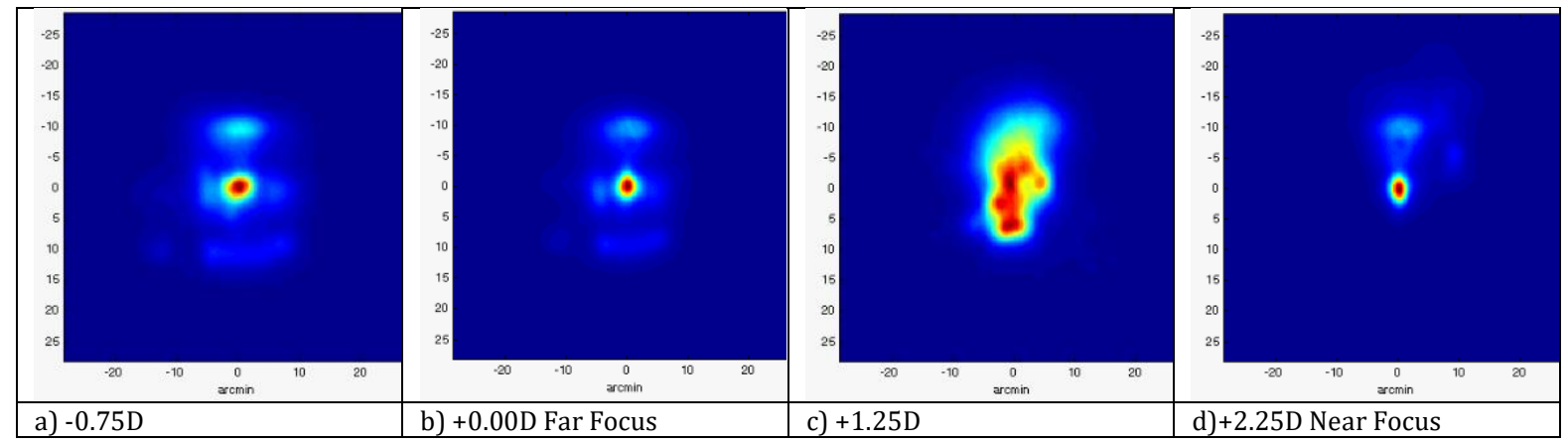

Fig.5: Double-pass images of a non-concentric refractive MIOL (Power $=+20.00 \mathrm{D} /$ Addition $=+2.75 \mathrm{D})$. The power indicated in the images is the value of the accommodative stimuli per each one.

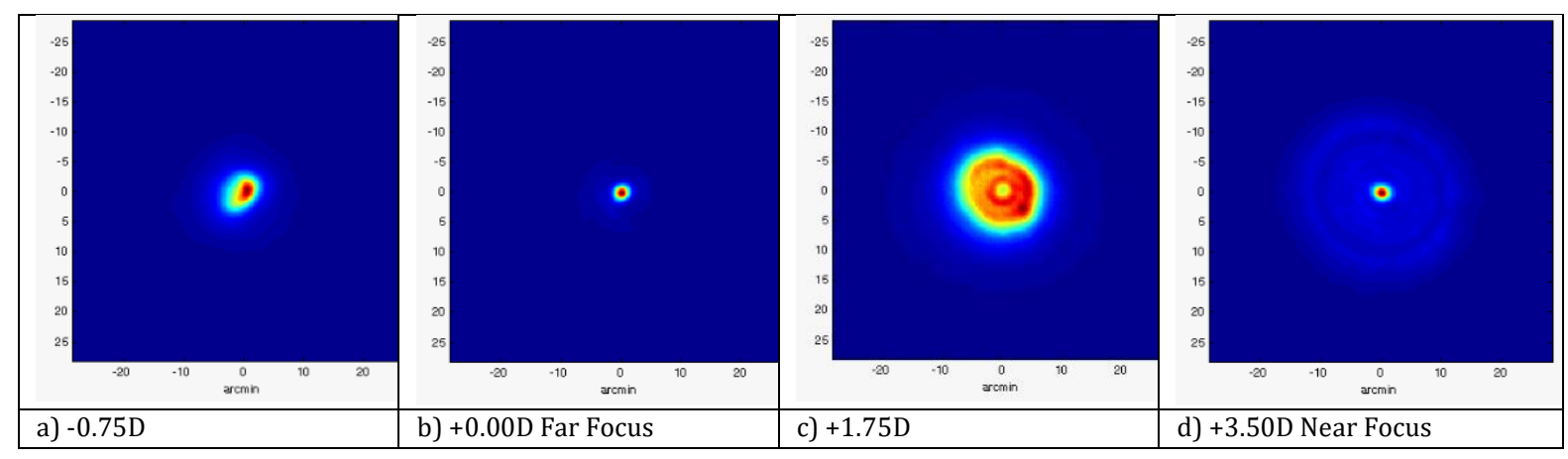

Fig.6: Double-pass images of the concentric diffractive MIOL (AcrySof® IQ ReSTOR® SN6AD1) (Power = +21.00D / Addition = $+3.00 \mathrm{D}$ ). The power indicated in the images is the value of the accommodative stimuli per each one.,

In order to support the imaging results, the values of the FWHM, the MTF cut-off and Strehl ratio for the through-focus are also presented in Fig 7. The near and the far focus were determined taking into account the numerical results of these three parameters (minimization of the FWHM, and maximization of the MTF cut-off and Strehl ratio). 


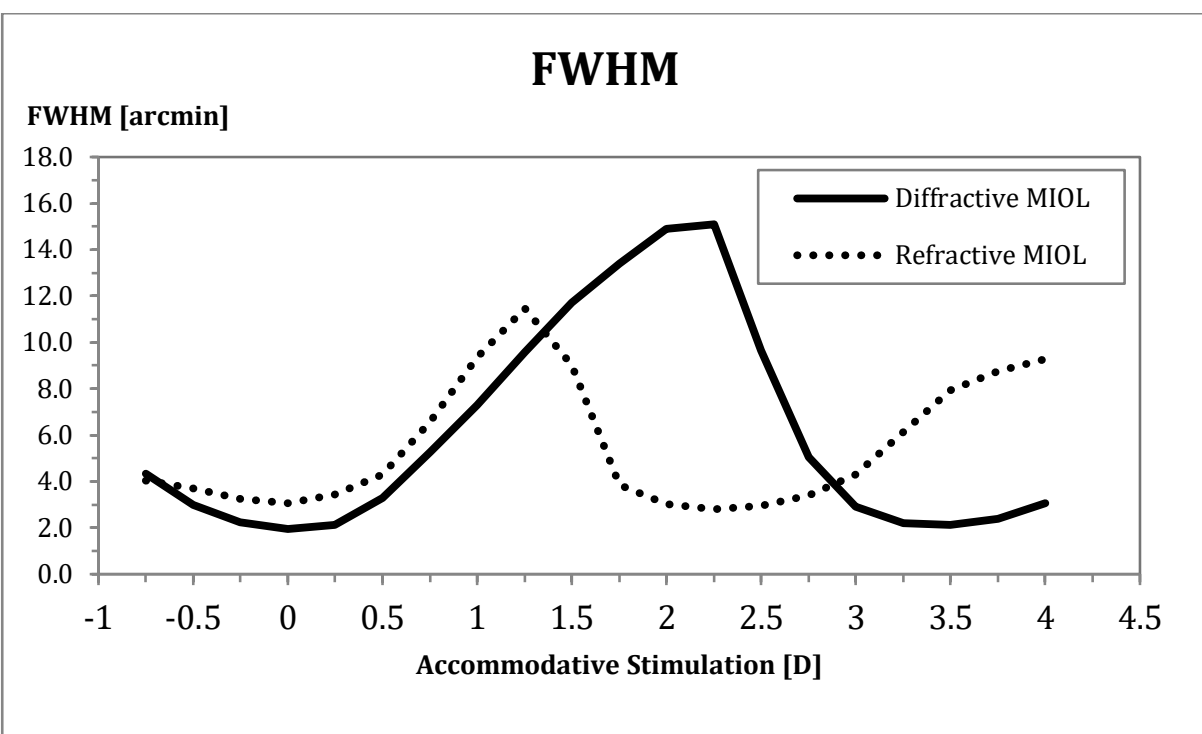

(a)

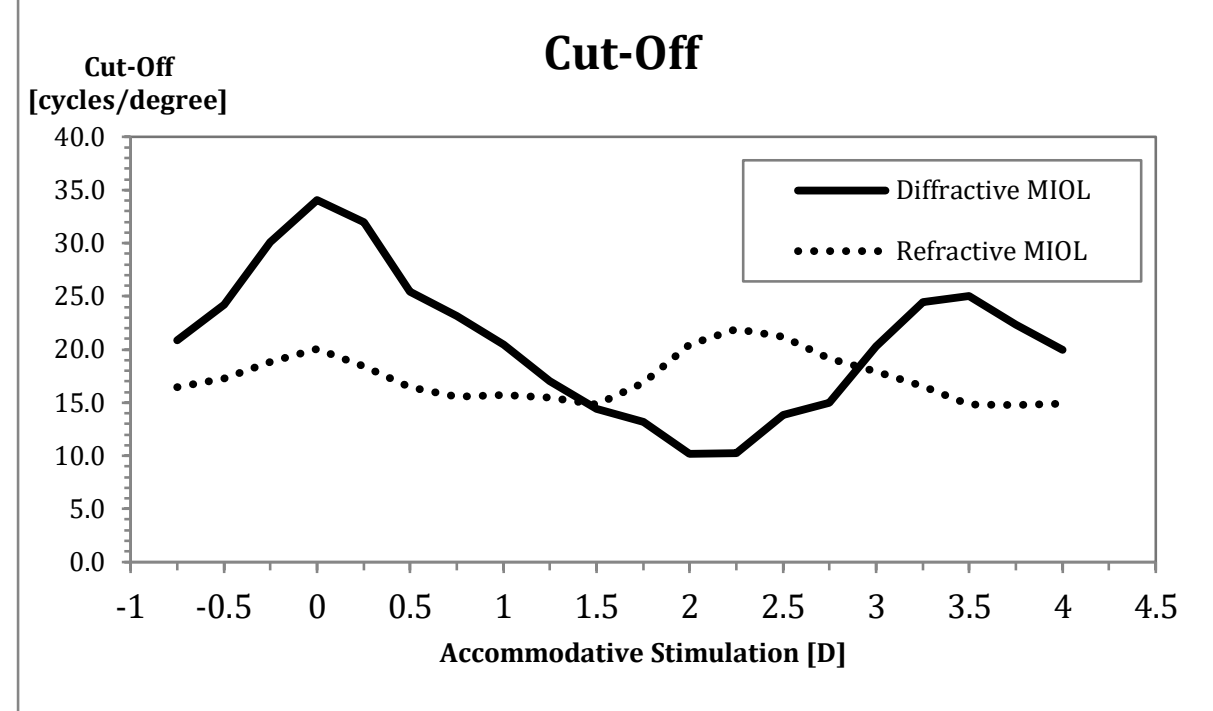

(b)

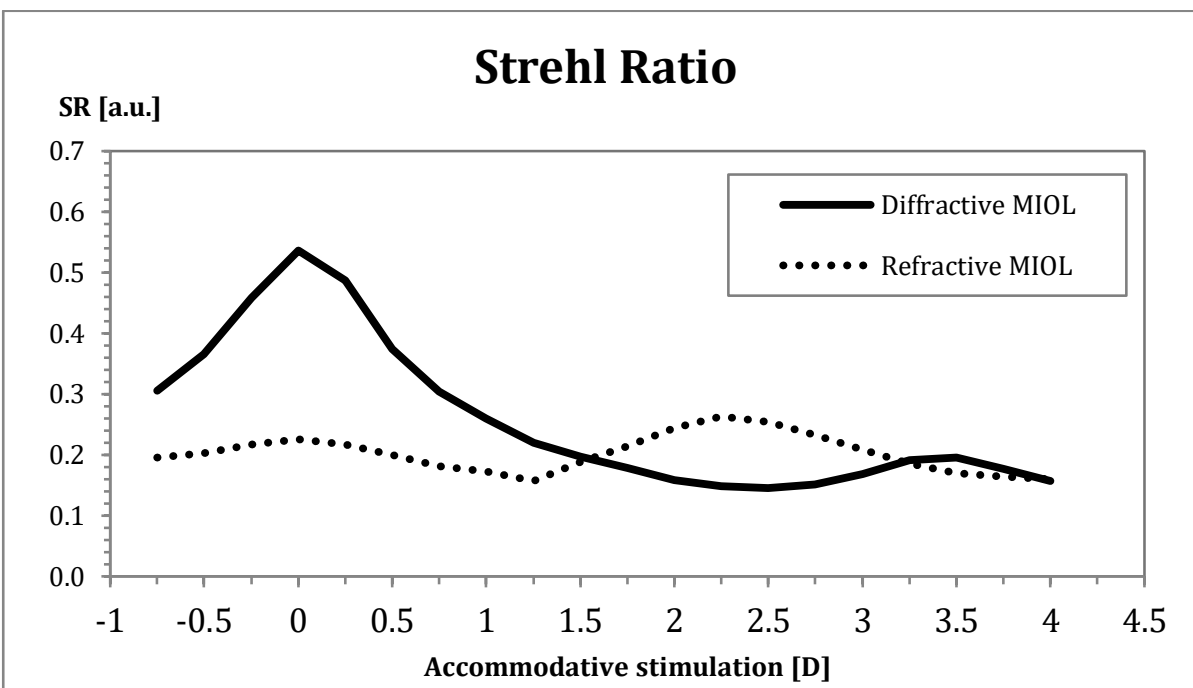

(c)

Fig.7: (a) FWHM values of the concentric diffractive and the non-concentric refractive MIOL along the through-focus; (b) MTF cutoff values of the diffractive and the refractive MIOL along the through-focus; (c) Strehl ratio values of the diffractive and the refractive MIOL along the through-focus. 
The diffractive MIOL has similar values of FWHM per both foci, being $1.94 \pm 0.11 \mathrm{arcmin}$ for the far focus and $2.10 \pm 0,10 \mathrm{arcmin}$ for the near one. However, the curves of the MTF cut-off and the Strehl ratio indicate that the optical quality of the far focus is significantly better than the near focus. The numerical results of the MTF cut-off and the Strehl ratio are $34.05 \pm 0,18$ cycles/degree and $0.54 \pm 0.01$ for the far focus and $25.01 \pm$ 0.27 cycles/degree and $0.20 \pm 0.003$ for the near focus.

In the case of the refractive MIOL, values of FWHM are also similar for each focus, $3.06 \pm 0.10 \mathrm{arcmin}$ for far focus and $2.8 \pm 0.14$ arcmin for near focus. In contrast with the diffractive MIOL, the curves of the MTF cutoff and the Strehl ratio of the refractive MIOL show that the near focus has similar results with the far focus. In particular, the numerical results are $20.05 \pm 0.14$ cycles/degree and $0.23 \pm 0.003$ for the far focus and $21.91 \pm 0.11$ cycles/degree and $0.26 \pm 0.008$ for the near focus.

\section{Conclusions}

A through-focus has been able to perform with a refractive MIOL and with a diffractive MIOL implanted in a customized wet model eye. In both cases, the imaging and the numerical results determine the far and the near focus.

These results show that the DP system with asymmetric focus permits the evaluation of the optical quality of the different distances vision that MIOLs have, while the point source projected on the retina on the firstpass is always on focus. This is not possible to perform with the commercial systems based on double-pass techniques that work with a symmetric focus.

One limitation that this system has is the fact that only MIOLs or MCLs with a central vision zone of $2 \mathrm{~mm}$ or bigger can be evaluated. If the central vision zone is less than $2 \mathrm{~mm}$, the laser beam of the first-pass would pass through different vision zones, affecting the point source projected on the retina. This situation not allows a proper evaluation of the optical quality.

In terms of behaviour of the MIOLs, the results show that the optical quality of the far focus is better for the diffractive MIOL than for the refractive one. The optical quality for near focus is similar for both. These facts are in accordance with some studies published by Barisic et al. [22] and Zelichowska et al. [23], where both concluded that the results obtained with patients implanted with diffractive MIOLs showed a better subjective performance than the patients implanted with refractive ones.

Taking into account all these facts, the main conclusion of this study is that the developed new compact open-field double-pass system with asymmetric focus is suitable to evaluate the optical quality of multifocal systems adapted or implanted in the eye. Nevertheless, this study is the first step of the validation of the system. Consequently, a future work with "in-vivo" measurements will be performed.

\section{Acknowledgements}

This study was partially funded by the Spanish Ministry of Science and Innovation and the European Union with the project grant DPI2011-30090-C02-01. A. Giner thanks the Ministry of Economy and Competitiveness for the PhD grant BES-2012-054777 she received. 